oxalate is formed at the same time, which dissolves a certain amount of magnesium oxalate forming the double oxalate; only it then forms that peculiar crystallization to which we wished to confine our attention.

It is very remarkable that botrytis bassiana cultivated on nutritive gelatine produces oxalic acid in large quantities which I have separated in a crystalline form.

\title{
CLOSING ADDRESS DELIVERED BEFORE THE WORLD'S CONGRESS OF CHEMISTS, AUGUST 26, 1893 .
}

By ALbert B. PREscotT.

I $\mathrm{N}$ this closing hour of the Congress the chair would congratu-

1 late its members upon the great interest and value of its transactions. In the wide attendance of European and American chemists, in the weight of the papers in the several divisions of chemical science, in the constant and increasing attendance through the sessions of six crowded days, and in the hearty spirit of brotherly sympathy which has given life and happiness to all our labors, we have been favored beyond the most sanguine expectations. We in the United States know the chemists of Europe better than we did before this Congress. Surely we have the best of encouragement for the union of the chemists of the world in a series of great meetings of profit and acquaintance, the first one of which is now being concluded.

I know that I voice the sentiment of every member when I give our united thanks to those whose active and untiring exertions have carried so well all the arrangements of this meeting. Our thanks are due, first, to the American Chemical Society, who instituted the call for the Congress and now opens its journal to our proceedings. To our general chairman of the joint committee, Professor Wiley, of the United States Department of Agriculture, we have been indebted for most efficient attention in details. He took the position when it was not easy to find one to accept its labors and to face its uncertainties. The chairman of the committee on papers, Professor William McMurtrie, and assuredly the chairman of the committee from the Congress Auxiliary, Professor John H. Long, the local 
genius of our convention, will be remembered most gratefully by us all. I will not longer detain you from your personal farewells to each other, and now declare the Congress adjourned.

\section{HYDROGEN SULPHIDE GENERATOR.}

\section{BY H. G. SCFANCHE.}

Rectived Septemter 13,1894 .

THE form of generator shown in the annexed cut has proved itself, during seven years of lise, to always furnish an absolutely uniform supply of gas. The acid reservoir A deliv-

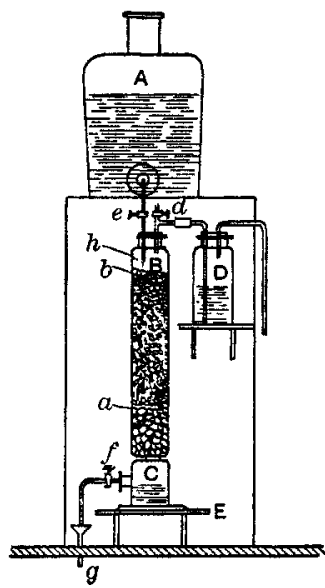
ers the acich into the generator $B$, containing ferrous sulphide, $a b$, resting on coarse pebbles at $a$. The ferrous chloride collects in $\mathrm{C}$ and may be drawn off, from time to time, by opening cocks $d$ and $f$, thus allowing it to flow through the lead pipe $g$ into a drip-pan underneath the table; $\mathrm{D}$ is an ordinary bottle for washing the gas. By regulating the flow of acid by means of the cock $e$, any supply of gas may be obtained, while the height of the column of ferrous sulphide, through which the acid percolates, assures an absolutely uniform supply of gas, as well as a complete neutralization of the acid. The shelf $E$, on which the generator $B$ rests, can be slipped off its bracket, thus facilitating the removal of $B$ for cleaning or charging.

[CONTRIBUTIONS FROM THE, CHEMTCAL LABORATORY, U. S. DEPARTMEAT OF AGRICULTURE, SENT BY H. W. WILEY, NO. I1.]

\section{MODIFICATION OF KNORR'S EXTRACTION APPARATUS.}

BY OMA CARR.

Receiverd October 15 is 8 gid.

TO avoid the inconveniences found with the usual form of mercury seal extractors, 'such as the expense of flasks, disturbance of the seal by unequal pressures, tendency of the mercury to enter the flask, etc., the modification shown in the drawing is suggested.

The tube a b may be of any convenient size adapted to the 1 Bulletin, No, 28, Division of Chemistry, p. 97. 